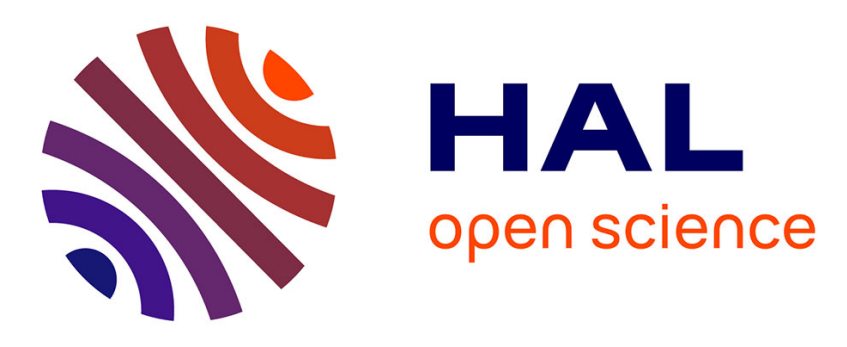

\title{
Bi-phasic water diffusion in sheet molding compound composite
}

\author{
Abir Abdessalem, Sahbi Tamboura, Joseph Fitoussi, Hachmi Ben Daly, Abbas \\ Tcharkhtchi
}

\section{- To cite this version:}

Abir Abdessalem, Sahbi Tamboura, Joseph Fitoussi, Hachmi Ben Daly, Abbas Tcharkhtchi. Bi-phasic water diffusion in sheet molding compound composite. Journal of Applied Polymer Science, 2020, 137 (7), pp.1-12. 10.1002/app.48381 . hal-02457688

\section{HAL Id: hal-02457688 https://hal.science/hal-02457688}

Submitted on 28 Jan 2020

HAL is a multi-disciplinary open access archive for the deposit and dissemination of scientific research documents, whether they are published or not. The documents may come from teaching and research institutions in France or abroad, or from public or private research centers.
L'archive ouverte pluridisciplinaire HAL, est destinée au dépôt et à la diffusion de documents scientifiques de niveau recherche, publiés ou non, émanant des établissements d'enseignement et de recherche français ou étrangers, des laboratoires publics ou privés. 


\title{
Bi-phasic water diffusion in sheet molding compound composite
}

\author{
Abir Abdessalem, ${ }^{1,2}$ Sahbi Tamboura, ${ }^{2}$ Joseph Fitoussi, ${ }^{1}$ Hachmi Ben Daly, ${ }^{2}$ Abbas Tcharkhtchi $\mathbb{1}^{1}$ \\ ${ }^{1}$ Laboraoire PIMM, Arts et Métiers ParisTech, CNRS Cnam, HESAM Université, 151 bd de l'Hôpital, 75013, France \\ ¿Laboratoire Mécanique de Sousse, Ecole Nationale d'Ingénieurs de Sousse (ENISo)-Université de Sousse, Pôle Technologique de \\ Sousse, 4054, Sousse, Tunisie \\ Correspondence to: A. Tcharkhtchi (E-mail: abbas.tcharkhtchi@ensam.eu)
}

\begin{abstract}
Sheet molding compound (SMC) composite has been studied under humid-aging conditions. Diffusion of water within the material, as measured by gravimetry, was found to be in good agreement with the "Langmuir-type" diffusion model developed by Carter and Kibler. In their theory, Carter and Kibler consider the existence of two types of water molecules in the material, «mobile» and «bound». In this study, these two types have been considered separately. Furthermore, Infrared spectroscopy (FTIR) analysis has been performed by decomposition of signals to study the fraction of free (mobile) and hydrogen-bounded water. Thermal analysis and microscopic observations were put forward to explain the two types of water molecules. In this contribution, we found a "bi-phasic" water diffusion. We suggest that the «mobile» water corresponding to the diffusion in the micro-porosities follows a Fickien kinetic, which turns to sigmoidal one at a specific time of immersion $\tau$. Whereas the kinetic of «bound» water, referring to crosslinking and plasticization, follows a sigmoidal kinetic, which turns to Fickien behavior when the overall network is saturated.
\end{abstract}

KEYWORDS: ageing; composites; glass transition; microscopy; spectroscopy

\section{INTRODUCTION}

Glass fiber reinforced unsaturated polyester composites (GFRUPC) are materials largely used in applications such as construction structure, cars tailgate, boat hulls, pipes, and so forth. However, extended exposure to environmental conditions such as humidity and temperature can lead to damage. Different studies have been carried out in the recent years to better assessing of the impact of these factors and understanding of the degradation mechanisms. ${ }^{1-10}$ Initially, physical aging would seem to be a reversible damage and the main consequence of water absorption is plasticization, leading to a decrease in the glass transition temperature $\left(T_{g}\right)$ and the material properties. This effect can be eliminated after water desorption and a return to nonaged properties can be almost obtained. ${ }^{4,6,8,11}$ Further, aging causes irreversible damage such as hydrolysis and cracking propagation. ${ }^{12-15}$ In this study, we only discuss physical aging.

Diffusion of moisture within the composite material and its kinetics are widely related to the degradation mechanisms. In order to be able to study water aging of composite material in a limited time, it is necessary to have an accelerated method. In this study, water aging was accelerated using high temperatures.

Different diffusion models can be used to explain water uptake. The simplest one is the Fickian behavior. ${ }^{15-17}$ However, deviation from this classical model are often observed. ${ }^{7,10,18}$ The two-phase diffusion model proposed by Carter and Kibler ${ }^{19}$ and referred to "Langmuir-type" absorption can successfully describe water absorption of many composite systems. ${ }^{7,10,20,21}$ It considers the existence of bound and free water molecules in the material with $\gamma$ is the probability per unit time (in $\mathrm{s}^{-1}$ ) for free water molecules to become bound and $\beta$ is the probability per unit time (in $\mathrm{s}^{-1}$ ) for bounded water to become free. Considering $\mathrm{n}(\mathrm{t})$ and $\mathrm{N}(\mathrm{t})$, respectively, the mobile and bound water molecules at time $t$ per unit volume, at equilibrium, we have:

$$
\gamma \mathrm{n}_{\infty}=\beta \mathrm{N}_{\infty}
$$

Many studies have been carried out to show the existence of bound and mobile water in the material, as reviewed by Popineau et $\mathrm{al}^{22}$ who themselves used nuclear magnetic resonance (NMR) as their main experimental technique to differentiate between the two types of water molecules. Many propositions have been made to explain the dual sorption invoking hydrogen bonding, nonhomogenous morphology, ${ }^{23,24}$ and voids within the polymer. ${ }^{25}$

Despite the referred literature, an unambiguous answer of the relevant questions "what are the mechanisms of water sorption and how are defined the two types of water?" is still not found, but in this study, we attempt to give an explanation. The aim of this study is to answer these questions. Thus, both gravimetric 


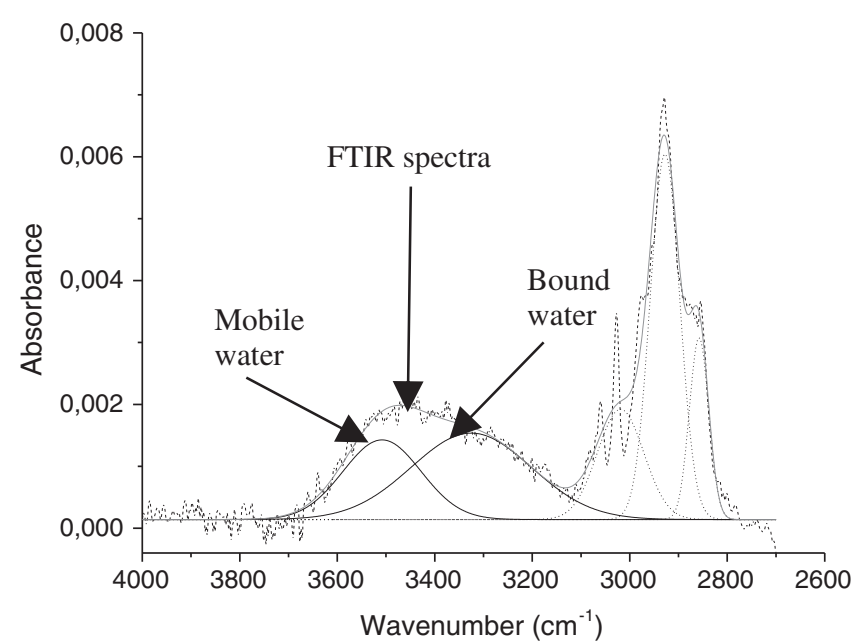

Figure 1. Example of FTIR spectra decomposition showing peaks decomposition into bound and mobile water

analysis and Fourier transform infrared spectroscopy (FTIR) studies were investigated on the SMC composite material at different times and temperatures of aging. This latter technique of FTIR is of interest since the decomposition of the obtained signals can describe the two water types.

Figure 1 shows the method used to decompose the FTIR spectra. ${ }^{26,27}$ The region from 3800 to $3100 \mathrm{~cm}^{-1}$ was deconvoluted into two peaks assuming that the band at low wavenumbers (3400-3200 $\mathrm{cm}^{-1}$ ) is referred to bounded water and the band at high wavenumbers $\left(3650-3580 \mathrm{~cm}^{-1}\right)$ is referred to mobile water. $^{28,29}$ Finally, dynamic mechanical analysis (DMA, France) test invoking glass transition temperature and scanning electron microscopy (SEM, France) observations were put forward to discuss the water diffusion impact.

\section{EXPERIMENTAL}

The material used was a thermoset unsaturated polyester resin reinforced with $28 \%$ of short glass fibers and $35 \%$ of calcium carbonate $\left(\mathrm{CaCO}_{3}\right)$. The chemical formula of the studied material is shown in Figure 2.

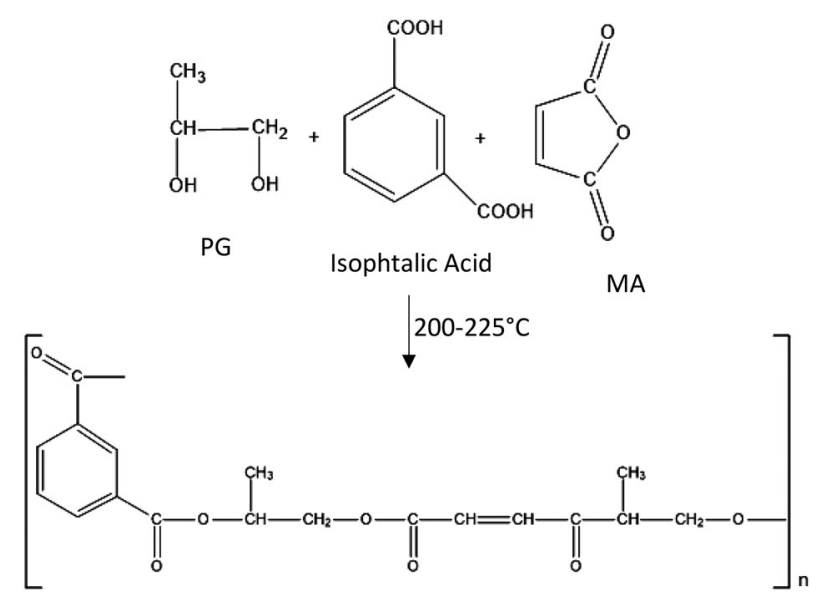

Figure 2. Chemical formula of SMC composite glass fiber reinforced unsaturated polyester resin ${ }^{30}$
The glass transition temperature of the nonaged material is $91^{\circ} \mathrm{C}$ obtained by DMA. All samples were dried in a vaccum oven at $60{ }^{\circ} \mathrm{C}$ over a period of 7 days before testing. Samples of $60 \times 15$ $\times 2 \mathrm{~mm}^{3}$ for gravimetric, DMA, FTIR analysis, and SEM observations were cut from the tailgate and were immersed in water at $25,50,70$, and $90^{\circ} \mathrm{C}\left( \pm 2{ }^{\circ} \mathrm{C}\right)$. Then they were weighed periodically on a METTLER AT261 balance (with a precision of $\pm 0.05 \mathrm{mg}$ ).

FTIR experiments were performed using a Spectrophotometer Frontier (Perkin Elmer, France). In order to obtain good signals, 32 scans were necessary at a range of $600-4000 \mathrm{~cm}^{-1}$. For each measure, three specimens were analyzed in attenuated total reflectance (ATR) mode. The ratio of areas of free and bound water signals was determined by spectral deconvolution using OriginPro program.

DMA tests were carried out using thermal analyzer (TA) to analyze the glass transition temperature. The measurements were obtained within a temperature range of $(-50)$ to $(150){ }^{\circ} \mathrm{C}$, using a heating rate of $2{ }^{\circ} \mathrm{C} / \mathrm{min}$ and under a constant frequency of $1 \mathrm{~Hz}$ in three points bending mode with a static force of $1 \mathrm{~N}$ and an amplitude of $25 \mu \mathrm{m}$.

Differential scanning calorimetric (DSC) tests were carried out on 5-8 mg of samples mass. The experiments were performed under nitrogen flow. The samples were heated from 20 to $250{ }^{\circ} \mathrm{C}$ with a heating rate of $10{ }^{\circ} \mathrm{C}$ per minute.

X-Ray microcomputed-tomography, France (EasyTom (Nano) from RX solutions) analysis was carried out on nonaged and aged at $90{ }^{\circ} \mathrm{C}$ samples after different aging times. The X-Act and Aviso softwares were then used, respectively, to obtain a $3 \mathrm{D}$ construction of the sample. The representative volume was of $6 \mathrm{~mm}$ $\times 6 \mathrm{~mm} \times 6 \mathrm{~mm}$.

SMC surfaces for microscopic observations were polished using a large flow of water. Then, a thin gold coating was made before the examination of the morphology of the GFRUPC under the SEM Hitachi 4800.

\section{Langmuir Model}

The basis of Carter and Kibler's model can be found in reference [19]. In this study, we summarize the needed information in our development. This model, referred to Langmuir-type diffusion, considers the existence of two types of water molecules in the material: free and bound. The molecular number densities at a given time $t$ and position $z$ verify the equations below in onedimensional case

$$
\begin{gathered}
\frac{\partial \mathrm{n}}{\partial \mathrm{t}}+\frac{\partial \mathrm{N}}{\partial \mathrm{t}}=\mathrm{D} \frac{\partial^{2} \mathrm{n}}{\partial^{2} \mathrm{X}} \\
\frac{\partial \mathrm{M}}{\partial \mathrm{t}}=\gamma \cdot \mathrm{n}-\beta \cdot \mathrm{N}
\end{gathered}
$$

With $D$ is the diffusion coefficient (constant), $n$ refers to the number of mobile water molecules per unit volume with a probability $\gamma$ to become bounded, and $N$ refers to the bound ones per unit volume with a probability $\beta$ to become free (mobile). Experimentally, for a specimen (with a thickness $e=2 \delta$ ) exposed to humid environment, the initial and boundary conditions verify 


$$
n(\mathrm{z}, 0)=0 \text { and } N(\mathrm{z}, 0)=0 \text { for }|\mathrm{z}|<\delta
$$

where $z=0$ is the central plane with surfaces at $z= \pm \delta$.

And

$$
n(\delta, t)=n_{\infty} \text { and } \mathrm{N}(-\delta, t)=n_{\infty} \text { for all time } t
$$

At time $t$ and a thickness $z$, the number of $n$-type water molecules is reference [19]

$$
\begin{aligned}
n(\mathrm{z}, \mathrm{t})= & n_{\infty}\left\{-\frac{4}{\pi} \sum_{n=0}^{\infty} \frac{(-1)^{\mathrm{n}}}{(2 n+1)\left(\mathrm{r}_{2 n+1}^{+}-\mathrm{r}_{2 n+1}^{-}\right)}\right. \\
& {\left.\left[\mathrm{r}_{2 n+1}^{+} \mathrm{e}^{-\mathrm{r}_{2 n+1}^{-}}{ }^{\mathrm{t}}-\mathrm{r}_{2 n+1}^{-} \mathrm{e}^{-\mathrm{r}_{2 n+1}^{+}}{ }^{\mathrm{t}}\right] \cos \left(\frac{\pi(2 n+1) \mathrm{z}}{2 \delta}\right)\right\} } \\
& +n_{\infty} \frac{4}{\pi \beta} \sum_{n=0}^{\infty} \frac{(-1)^{n}}{(2 n+1)\left(\mathrm{r}_{2 n+1}^{+}-\mathrm{r}_{2 n+1}^{-}\right)}\left(\mathrm{r}_{2 n+1}^{+} \cdot \mathrm{r}_{2 n+1}^{-}\right) \\
& \times\left[\mathrm{e}^{-\mathrm{r}_{2 n+1}^{-}}{ }^{\mathrm{t}}-\mathrm{e}^{-\mathrm{r}_{2 n+1}^{+}}{ }^{\mathrm{t}}\right] \cos \left(\frac{\pi(2 n+1) \mathrm{z}}{2 \delta}\right)
\end{aligned}
$$

With

$$
\begin{aligned}
& \mathrm{r}_{2 n+1}^{ \pm}=\frac{1}{2}\left(\mathrm{k}(2 n+1)^{2}+\gamma+\beta\right) \\
& \pm \sqrt{\left(\mathrm{k}(2 n+1)^{2}+\gamma+\beta\right)^{2}-4 \mathrm{k} \beta(2 n+1)^{2}}
\end{aligned}
$$

And

$$
\mathrm{k}=\frac{\pi^{2} \mathrm{D}}{(2 \delta)^{2}}
$$

Many studies used the Carter and Kibler's theory to describe water diffusion in materials. In this study, we aim to separately consider the bound- and free-water molecules, $N(\mathrm{z}, \mathrm{t})$ and $n(\mathrm{z}, \mathrm{t})$, respectively. The rearrange and the resolution of equation (3) by using the integration factor $\mathrm{e}^{\beta \mathrm{t}}$ leads to the equation below

$$
N(\mathrm{z}, \mathrm{t})=\delta \mathrm{e}^{\beta \mathrm{t}} \int n(\mathrm{z}, \mathrm{t}) \mathrm{e}^{\beta \mathrm{t}} \mathrm{dt}
$$

If we consider $\mathrm{M}$ the total number of water molecules at time $t(\mathrm{M}$ $(t)=n(t)+N(t))$ per unit area, perpendicular to $z$ in the material at saturation $(+\delta>z>-\delta)$, the equilibrium state is given by

$$
2 \delta\left(n_{\infty}+N_{\infty}\right)=\mathrm{M}
$$

Using eqs. (1) and (6), we obtain

$$
n_{\infty}=\frac{\beta}{\beta+\gamma} \frac{\mathrm{M}}{2 \gamma}
$$

We obtain with useful approximations and when $\beta$ and $\gamma \ll \mathrm{k}$

$$
\begin{gathered}
\frac{n(\mathrm{t})}{\mathrm{M}}=\frac{\beta}{\beta+\gamma}\left\{1-\frac{8}{\pi^{2}} \mathrm{e}^{-\mathrm{kt}}\right\} \\
\frac{N(\mathrm{t})}{\mathrm{M}}=\frac{\gamma \beta}{\beta+\gamma} \mathrm{e}^{-\beta \mathrm{t}}\left\{\frac{1}{\beta}\left(\mathrm{e}^{\beta \mathrm{t}}-1\right)-\frac{8}{\pi^{2} \mathrm{k}}\left(\mathrm{e}^{-\mathrm{kt}}-1\right)\right\}
\end{gathered}
$$

This equation can be simplified with judicious approximations, and we obtain
- For short exposure time

$$
\frac{\mathrm{N}(\mathrm{t})}{\mathrm{M}}=\frac{4}{\pi^{3 / 2}}\left(\frac{\beta}{\gamma+\beta} \mathrm{m}_{\infty}\right) \sqrt{\mathrm{kt}}
$$

- At a pseudo equilibrium, which appears at medium times

$$
\frac{N\left(\mathrm{t}_{\text {pseudo-eq }}\right)}{\mathrm{M}}=\frac{\beta}{\beta+\gamma}
$$

- For long exposure time

$$
\frac{N(\mathrm{t})}{\mathrm{M}}=\left(1-\frac{\gamma}{\gamma+\beta} \mathrm{e}^{-\beta \mathrm{t}}\right)
$$

\section{RESULTS}

\section{Gravimetry}

It is convenient to represent water absorption behavior as a function of the square root of the exposure time in moisture. ${ }^{31}$ The normalized water uptake data (as mass uptake/mass at saturation) are plotted versus the normalized time given by $t^{0.5} / \mathrm{e}$ (where $e$ is the sample thickness).

The mass variation shows three behaviors. Firstly, for all the specimens, the water absorption process is linear and $\left(\frac{M_{t}-M_{0}}{M_{0}}\right)>0$. Then a decrease, at shifted periods of time, was recorded on the absorption curves where $\left(\frac{M_{t}-M_{0}}{M_{0}}\right)<0$. This phenomenon is so much faster when the temperature is higher. Finally, the diffusion restarts again in the material until the saturation, as it is shown in the absorption curve at $90^{\circ} \mathrm{C}$ (Figure 3 ).

To understand the origins of the mass drop, different tests were carried out.

- Firstly, It would be interesting to follow the water desorption of aged specimens by drying in a vacuum oven. The mass evolution was followed continuously by gravimetric measurements and the results are shown in Figure 4.

It is obvious that the drying phenomenon decreases the samples mass. From a certain drying time, the mass remains constant and lower than $\mathrm{M}_{0}$. This may be due to additive release initially present in the sample.

The mass loss was quantified as follow. The initial sample's mass was recorded $\left(\mathrm{M}_{0}\right)$. After immersion, water uptake $\left(M_{\text {water }}\right)$ increases in the material. Then the total sample's mass $\left(M_{1}\right)$ decreases due to additive release $\left(M_{1}=M_{0}+M_{\text {water }}-M_{\text {additive }}\right)$. At the end of drying process, the mass $\left(M_{2}\right)$ was noted. These steps are explained in Figure 5.

Samples aged at $90{ }^{\circ} \mathrm{C}$ recorded a decrease of $0.48 \%$ for samples aged at $90{ }^{\circ} \mathrm{C}$ compared to the initial mass $\left(M_{0}\right)$. The specimen mass decreases of about $0.35 \%$ at $70{ }^{\circ} \mathrm{C}$ and $0.15 \%$ at $50{ }^{\circ} \mathrm{C}$ compared to $M_{0}$. However at $25{ }^{\circ} \mathrm{C}$, a decrease of only $0.05 \%$ was recorded.

- At the same time, the outer surfaces of the aged specimens were visually controlled after different immersion times. The observations are illustrated in Figure 6. White substance was 

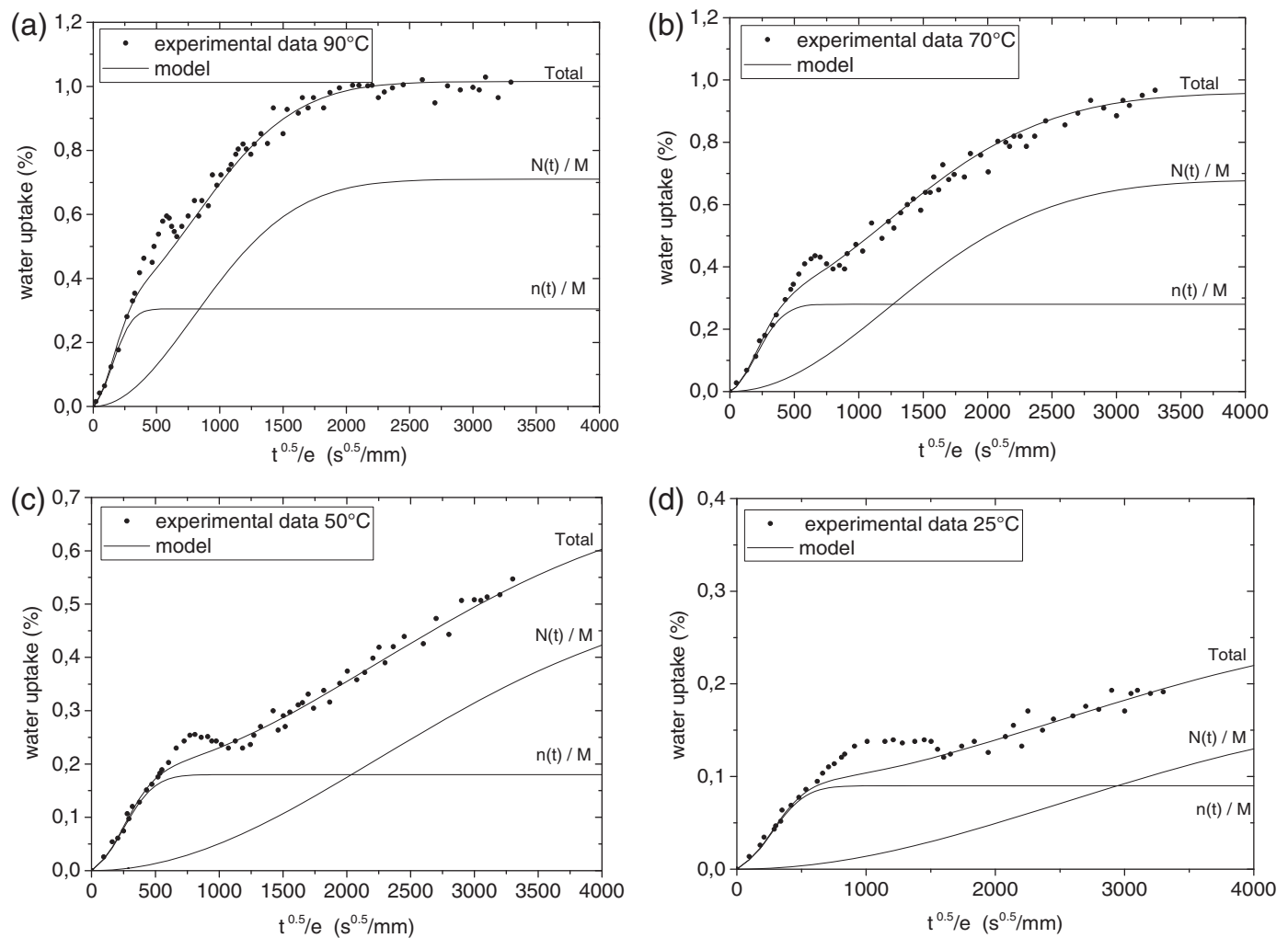

Figure 3. Gravimetric results for water absorption at (a) $90^{\circ} \mathrm{C}$, (b) $70^{\circ} \mathrm{C}$, (c) $50{ }^{\circ} \mathrm{C}$, and (d) $25^{\circ} \mathrm{C}$. (-) experimental, ( -) model.
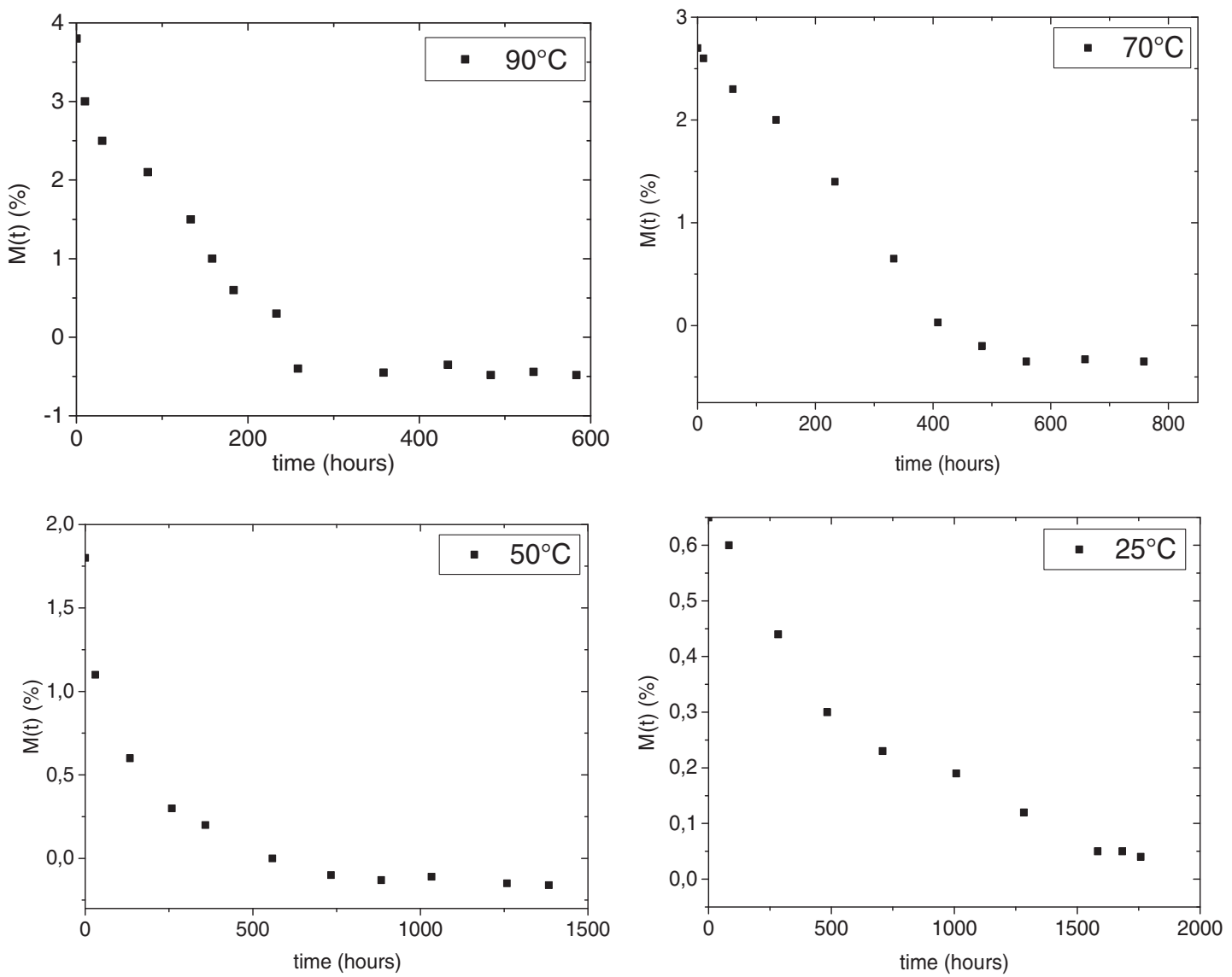

Figure 4. Gravimetric results during desorption at different temperatures. 


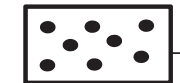

$M_{0}$

- CaCQparticles

- Water

Figure 5. Quantification of mass loss recorded in the sorption curves.

(A)

(a)

(b)

(c)

\section{(d)}

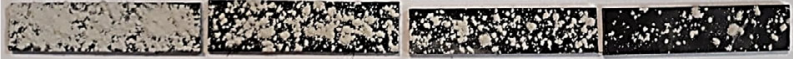

Figure 6. samples' surfaces of (a) unaged, and after (b) 100 h, (c) 500 and (d) 2500 of aging at (A) $90^{\circ} \mathrm{C}$, (B) $70^{\circ} \mathrm{C}$, (C) $50{ }^{\circ} \mathrm{C}$, and (D) $25^{\circ} \mathrm{C}$ presenting different density of white spots due to of $\mathrm{CaCO}_{3}$ release. [Color figure can be viewed at wileyonlinelibrary.com]

observed on the outer surfaces of the aged samples whose origins are unknown.

Results in infrared-spectroscopy of these white particles are shown in Figure 7. Two main peaks were identified. The first is located

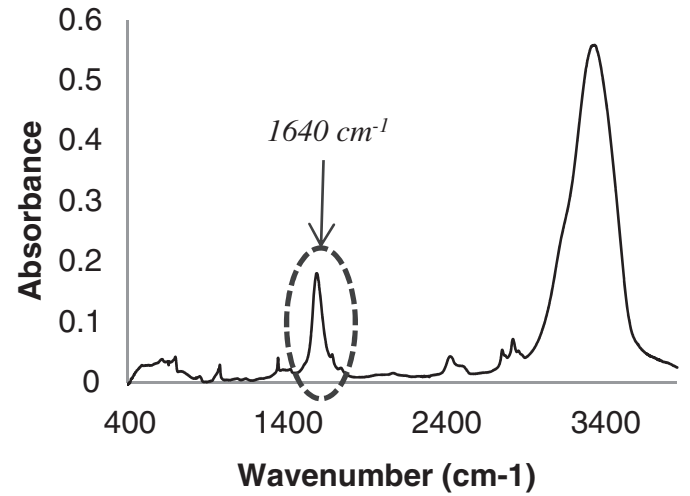

Figure 7. FTIR spectra showing the presence of $\mathrm{CaCO}_{3}$ particles.

between the wavenumbers of 3500 to $3200 \mathrm{~cm}^{-1}$, corresponding to water molecules. The second peak was around the wavenumber $1650 \mathrm{~cm}^{-1}$ referring thus to calcium carbonate $\left(\mathrm{CaCO}_{3}\right)$.

- Another test was carried out on aged at $90^{\circ} \mathrm{C}$ and nonaged samples using X-ray micro-tomography. A 3D representation of the $\mathrm{CaCO}_{3}$ distribution in the considered volume is illustrated in Figure 8.

The results show a high concentration of carbonate calcium particles both in the inner and outer areas of the nonaged sample.

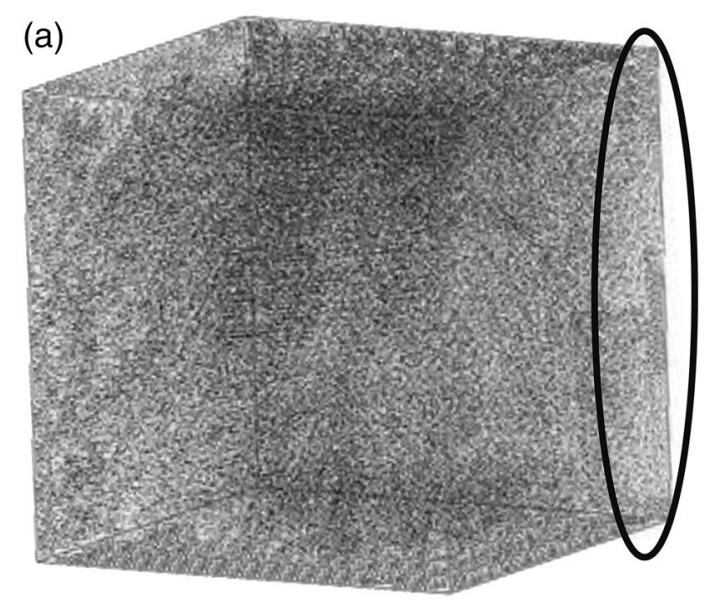

(b)

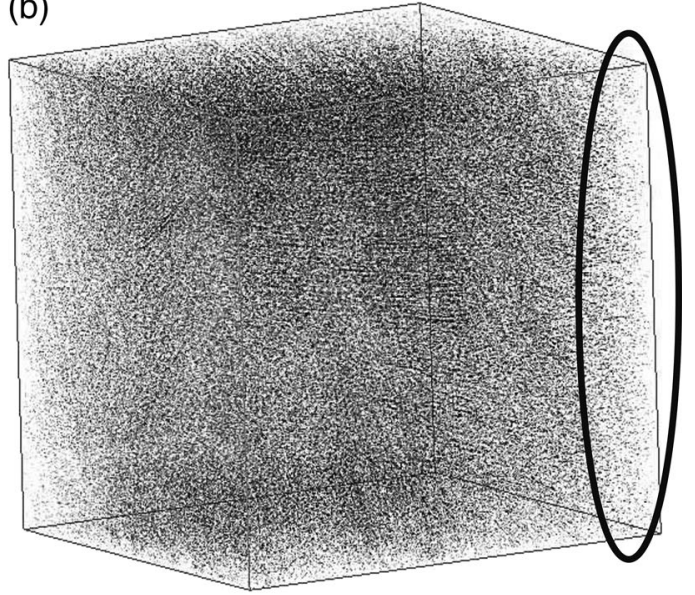

(c)

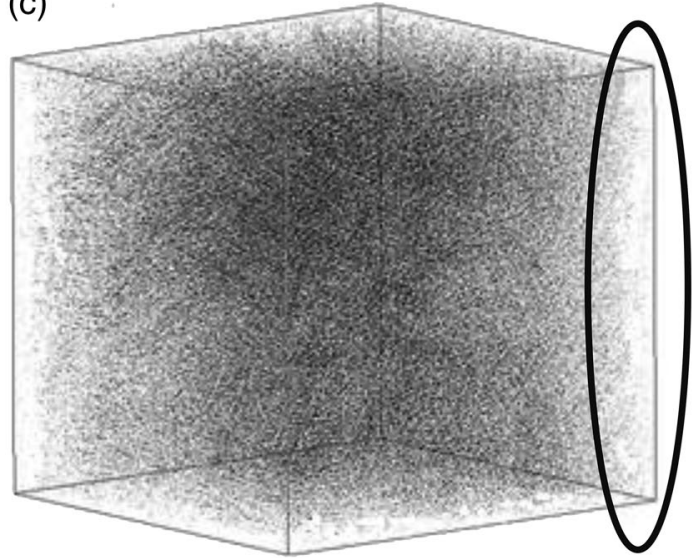

(d)

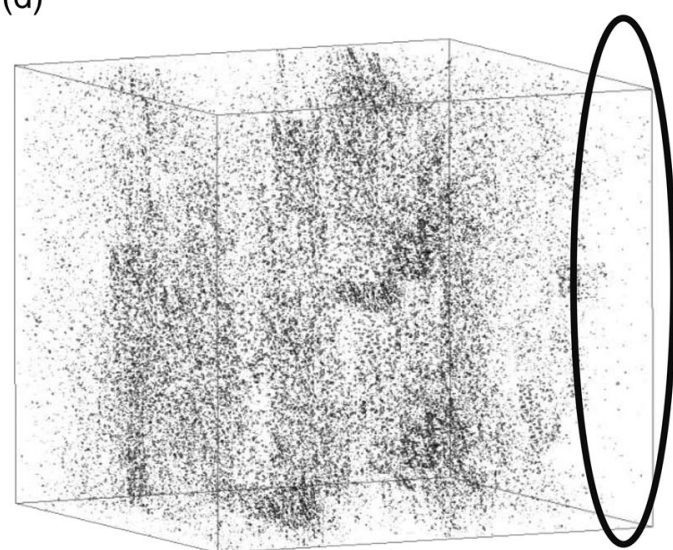

Figure 8. 3D distribution of $\mathrm{CaCO}_{3}$ in (a) the non-aged sample, and aged at $90{ }^{\circ} \mathrm{C}$ after (b) $500 \mathrm{~s}^{0.5} / \mathrm{mm}$, (c) $700 \mathrm{~s}^{0.5} / \mathrm{mm}$, and (d) $1000 \mathrm{~s}^{0.5} / \mathrm{mm}$. 


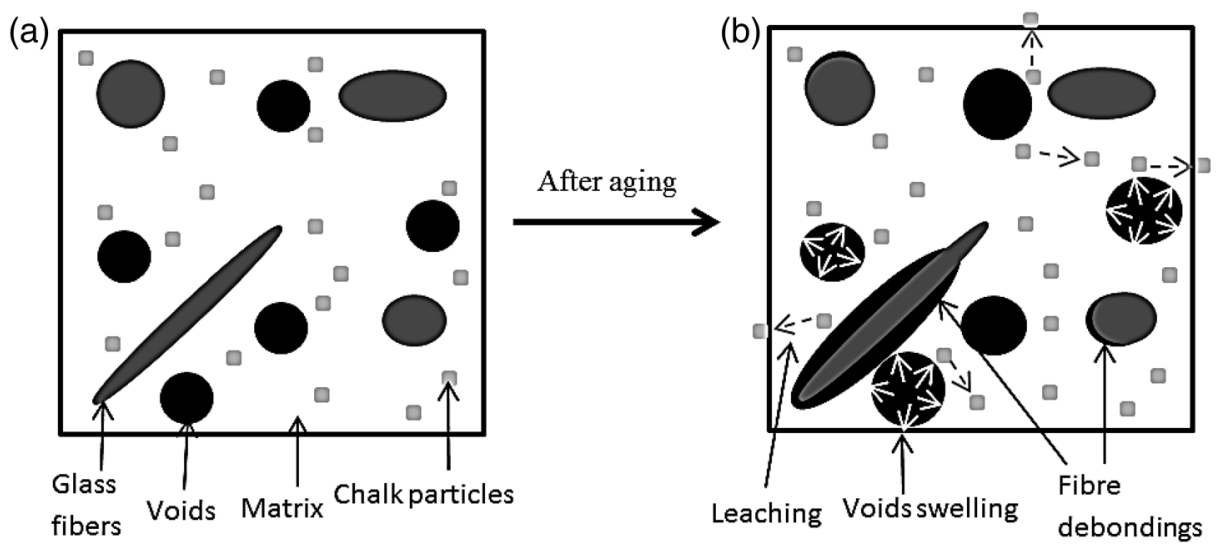

Figure 9. Schematic description of swelling and leaching of $\mathrm{CaCO}_{3}$ particles due to water diffusion in the existent voids (a) initially before aging and (b) after aging.

The $90{ }^{\circ} \mathrm{C}$-aged samples, show a decrease in concentration, particularly in areas near the outer surfaces, due to water attack.

All these results confirm that the mass loss is due to carbonate calcium release.

This phenomenon can be attributed to osmosis degradation. Indeed, the diffusion of water molecules, by capillarity, ${ }^{32,33}$ in the existing porosities in the matrix increases their sizes. This increase induces local stresses. The generated stress causes an increase in the pressure usually called "osmotic pressure." This pressure, which increases gradually, affects the neighboring zones of the matrix, rich in $\mathrm{CaCO}_{3}$, and therefore facilitated the release of the calcium carbonate particles. These scenarios are explained in Figure 9.

In Figure $3\left(a^{-} d\right)$, we represent the experimental gravimetric results (black circles) and three curves: a continuous line, matching the experimental data, representing the overall moisture uptake $(\mathrm{M}(\mathrm{t}) / \mathrm{M})$, and so corresponding to eq. (12) and eq. (13). Continuous lines showing the relative fraction of free water $(\mathrm{n}(\mathrm{t}) / \mathrm{M})$ referring to eqs. (10) and bound ones $(\mathrm{N}(\mathrm{t}) / \mathrm{M})$ referring to eqs. (11) as defined by Carter and Kibler theory.

Table I shows the parameters used to well fit $(\mathrm{M}(\mathrm{t}) / \mathrm{M})$ with experimental data. These were determined as follow. ${ }^{7}$ For shortexposure time, the parameter D (or k) was calculated from experimental measurements. Then, at pseudo equilibrium, the ratio $\frac{\gamma}{\gamma+\beta}$ was obtained referring to eq. (14). For long exposure time, the eq (13) was fitted to experimental results with varying $\beta$ and finally $\gamma$ was deduced from eq (14).

The plotted theoretical curves are well matched with the experimental measurement. The absorption at saturation at the temperature range from 25 to $90{ }^{\circ} \mathrm{C}$ seems to be close in the range of
$615 \pm 0.4 \%$ (Table I). As the diffusion coefficient varies with temperature, we can assume its dependence to the classical Arrhenius law. A good correlation was obtained when plotting $\operatorname{Ln}(\mathrm{D})$ against $\frac{1}{\mathrm{~T}}$ as shown in Figure 10(a).

$$
\mathrm{D}=\mathrm{D}_{0} \exp \left(\frac{-\mathrm{E}_{\mathrm{D}}}{\mathrm{RT}}\right)
$$

Where $D_{0}$ is a constant, $E_{D}$ is the activation energy, $T$ is the temperature $(\mathrm{K})$, and $\mathrm{R}=8.32 \cdot 10^{-3} \mathrm{~kJ} \cdot \mathrm{K}^{-1} \cdot \mathrm{mol}^{-1}$ is the gas constant.

The method used to calculate $\mathrm{D}$ does not take into account the edge effects, which result in the absorption of water by the material sides. This value can be corrected by the following expression $^{34,35}$

$$
\mathrm{D}_{\text {corrected }}=\mathrm{D} \cdot\left(1+\frac{\mathrm{e}}{\mathrm{L}}+\frac{\mathrm{e}}{\mathrm{l}}\right)^{-2}
$$

With respectively e, $\mathrm{L}$, and 1 are the thickness, length, and width of the specimen.

Both $\beta$ and $\gamma$ were obtained from the finest fitting of Carter and Kibler theory to experimental results (Table I). These parameters describe an Arrhenius-type temperature dependence as shown in Figure 10(b). Activation energies for $\beta, \gamma$, and D were found about $59 \mathrm{KJ} \cdot \mathrm{mol}^{-1}( \pm 1 \mathrm{KJ} / \mathrm{mol})$ (Table II), which is typical for thermally activated polymer systems.

\section{SEM Observations}

The evolution of microstructure before and after aging is shown in Figure 11.

Table I. Carter and Kiblers' Parameters Corresponding to the Finest Fitting of Carter and Kibler Theory to Experimental Results

\begin{tabular}{lllll}
\hline & $25{ }^{\circ} \mathrm{C}$ & $50{ }^{\circ} \mathrm{C}$ & $70{ }^{\circ} \mathrm{C}$ & $90{ }^{\circ} \mathrm{C}$ \\
\hline Weight at saturation (\%) & $5.9 \pm 0.2$ & $6.5 \pm 0.2$ & $6.1 \pm 0.2$ & $6.22 \pm 0.2$ \\
Weight at pseudo-eq (\%) & $0.6 \pm 0.2$ & $1.3 \pm 0.2$ & $1.67 \pm 0.2$ & $1.8 \pm 0.2$ \\
$D\left(\mathrm{~mm}^{2} / \mathrm{s}\right)$ & $6.9 \pm 0.3 \times 10^{-7}$ & $5.3 \pm 0.2 \times 10^{-6}$ & $1.4 \pm 0.2 \times 10^{-5}$ & $3.4 \pm 0.1 \times 10^{-5}$ \\
$\beta\left(\mathrm{s}^{-1}\right)$ & $4 \pm 0.1 \times 10^{-9}$ & $1.5 \pm 0.1 \times 10^{-8}$ & $4.5 \pm 0.1 \times 10^{-8}$ & $1.97 \pm 0.1 \times 10^{-7}$ \\
$\gamma\left(\mathrm{s}^{-1}\right)$ & $1.08 \pm 0.1 \times 10^{-8}$ & $1.13 \pm 0.1 \times 10^{-7}$ & $2.5 \pm 0.1 \times 10^{-7}$ & $5.17 \pm 0.1 \times 10^{-7}$ \\
\hline
\end{tabular}



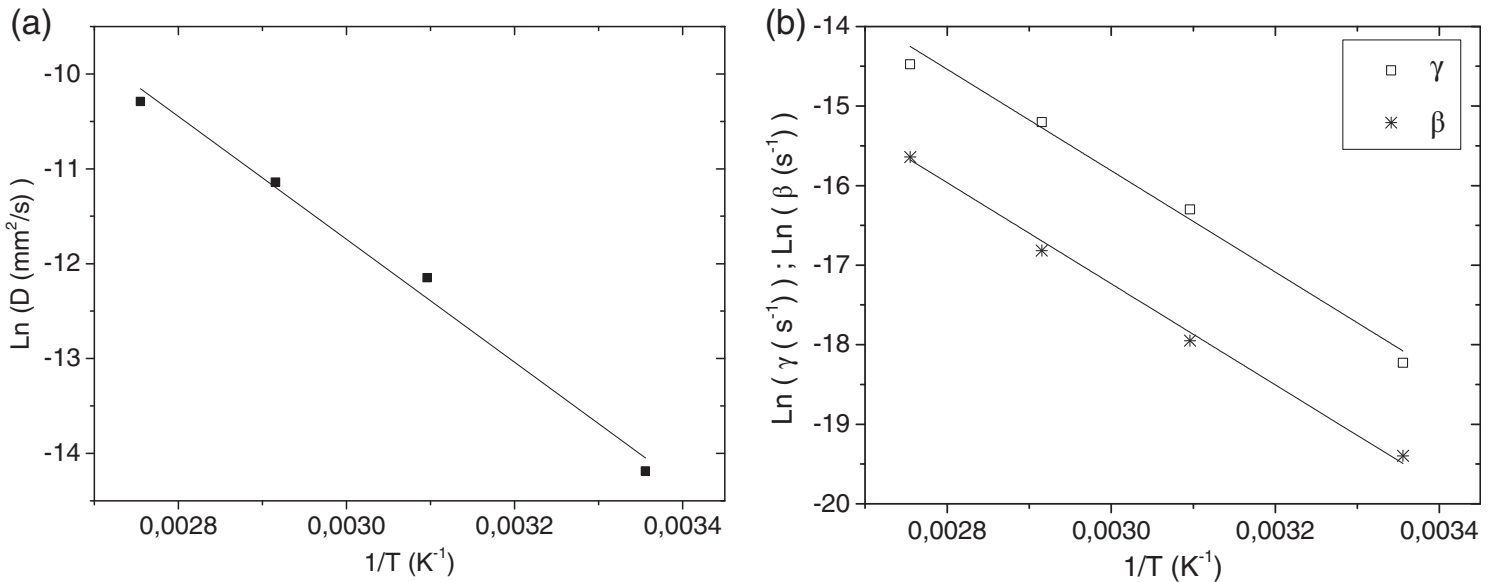

Figure 10. Arrhenius representation of (a) the diffusion coefficient $\mathrm{D}$, and (b) $\beta$ and $\gamma$ on logarithmic scale versus $1 / \mathrm{T}$.

Table II. Activation Energy of the Diffusion Parameters D, $\beta$, and $\gamma$

\begin{tabular}{llll}
$\mathrm{E}_{a}^{\mathrm{D}}\left(\mathrm{KJ} \cdot \mathrm{mol}^{-1}\right)$ & $\mathrm{E}_{\mathrm{a}}^{\beta}\left(\mathrm{KJ} \cdot \mathrm{mol}^{-1}\right)$ & $\mathrm{E}_{a}^{\gamma}\left(\mathrm{KJ} \cdot \mathrm{mol}^{-1}\right)$ & Error $\left(\mathrm{KJ} \cdot \mathrm{mol}^{-1}\right)$ \\
\hline 59.6 & 58.4 & 59.3 & \pm 1 \\
\hline
\end{tabular}

Figure 11(a) shows the nonaged material's surface where some microporosities can be distinguished in the matrix.

A first mode of degradation is observed in the aged samples, which is matrix damage. The main reason of such degradation is related to the existence of porosities in the studied composite. These porosities enhance matrix degradation as they provide pathways for water penetration. The explanation given for the appearance of these damages puts into question the osmotic pressure developed within the material.

After $100 \mathrm{~h}$ of aging, it was observed that the size increases from 8 to $9.6 \mu \mathrm{m}$ and $16.1 \mu \mathrm{m}$ at 50 and $90{ }^{\circ} \mathrm{C}$, respectively, with a rate of 2.1 and $7.9 \%$. However, after $500 \mathrm{~h}$ of aging, a degradation of only the matrix was observed at $50{ }^{\circ} \mathrm{C}$, whereas, at $90{ }^{\circ} \mathrm{C}$, simultaneously with matrix degradation, a few cracks were found in the interface region (a decohesion between fiber and matrix) as it is shown in Figure 11(e).

Similar degradations were observed in samples aged at $70{ }^{\circ} \mathrm{C}$ but a little less than those described at $90{ }^{\circ} \mathrm{C}$ after the two periods of immersion $(13 \mu \mathrm{m}$ of size with a rate of $4.5 \%$ after only $100 \mathrm{~h}$ in immersion). After $100 \mathrm{~h}$ at $25^{\circ} \mathrm{C}$, there are no noticeable changes. However, after $500 \mathrm{~h}$, a matrix degradation, caused by porosities filling, was detected but much less then that observed at $50{ }^{\circ} \mathrm{C}$ after $100 \mathrm{~h}(8.7 \mu \mathrm{m}$ corresponding to an increasing rate of $1.2 \%)$.

The voids size evolution during aging in water immersion at different temperature is shown in Figure 12. At each time, the average size was obtained based on 5 micrographs.
By the end of the aging process, fibers and matrix completely deboned at 70 and $90{ }^{\circ} \mathrm{C}$. In this context, Alawsi ${ }^{36}$ deduced that the humidity absorption can affect the adhesion between the matrix and the fibers. Similarly, Athijayamani ${ }^{37}$ showed that debondings of fiber/matrix interface is due to the attack of the interface by water molecules. Haddar ${ }^{35}$ explained that moisture destroy the adhesion between fibers and matrix, which lead to the mass gain of the samples.

\section{Infrared Spectroscopy}

After collecting the spectrum of the nonaged samples, the specimens were soaked in water. Then FTIR analysis was carried out at room temperature to collect the spectrum of the aged samples at different temperatures. The same sample was used to obtain both the dry and the wet spectrum. The results shown in Figure 13 are obtained after a base line correction on spectra of $90{ }^{\circ} \mathrm{C}$-aged samples. Similar trends were recorded at 25,50 , and $70{ }^{\circ} \mathrm{C}$ although not illustrated for brevity.

Often it was assumed that when analyzing in (ATR) mode, the thickness penetration of the infrared beam varies, and thus a normalization of the spectra is necessary. The aromatic ring, consisting of $(-\mathrm{C}=\mathrm{C}-)$ bonds, and presenting an absorption band at $1450 \mathrm{~cm}^{-1}$ is, theoretically, not sensitive to moisture. Hence, a correction can be made referring to its absorbance as described in the equation (17)

$$
\text { normalized Absorbance }=\frac{\text { Absorbance at } \mathrm{x}\left(\mathrm{cm}^{-1}\right)}{\text { Absorbance at } 1450\left(\mathrm{~cm}^{-1}\right)}=\frac{A}{A_{\text {ref }}}
$$

Quantitative analysis was carried out by spectra deconvolution over the wavenumber range of 3800 to $3200 \mathrm{~cm}^{-1}$. On the basis of previous experience of FTIR data, ${ }^{26}$ the areas of the total peak and the deconvoluted ones can be obtained. The ratio of the bound and mobile water peaks areas, converted into a relative sorption, can be estimated with equation (18)

$$
\text { relative absorption of free }(\text { or bound }) \text { water }(\mathrm{t})==\frac{\text { free }(\text { or bound }) \text { water peak area }}{\text { total peak area }} * \frac{\text { water absorption }(\mathrm{t})}{\text { water absorption }(\infty)}
$$




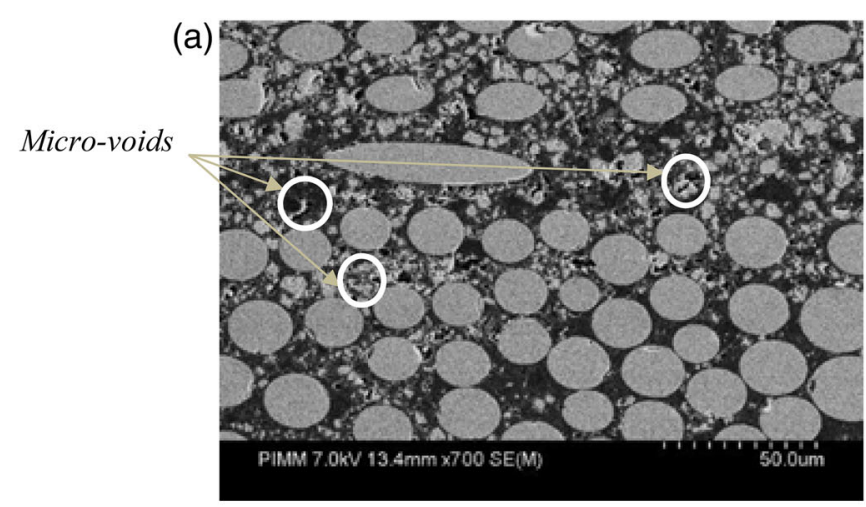

Micro-voids

(b)

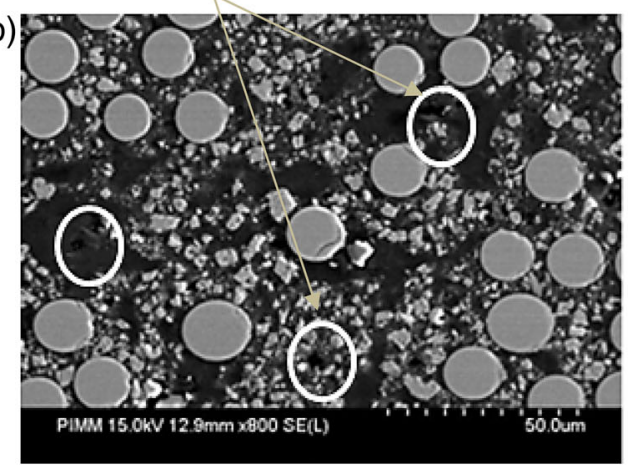

(d)

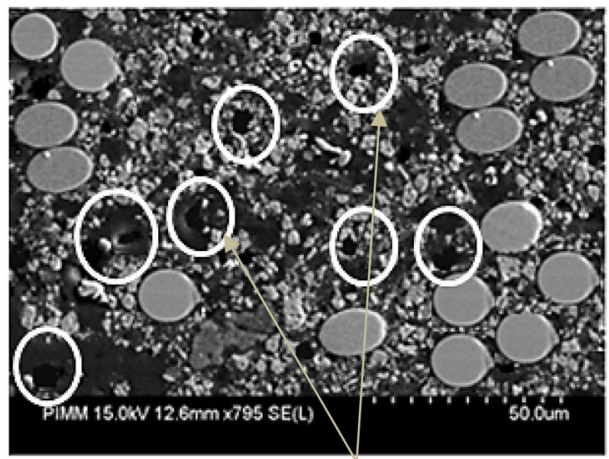

Micro-voids

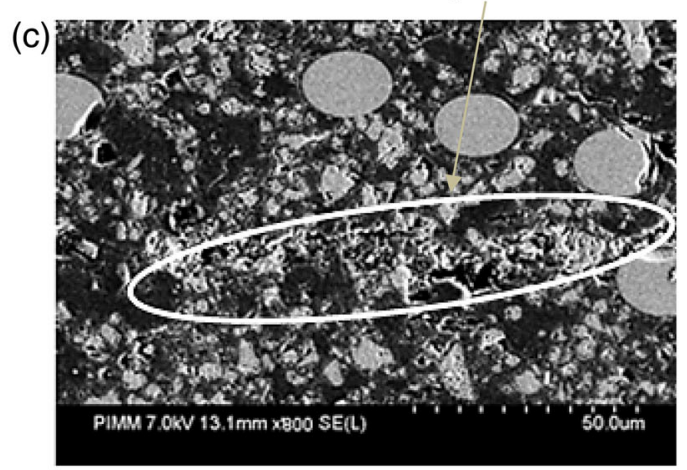

(e)

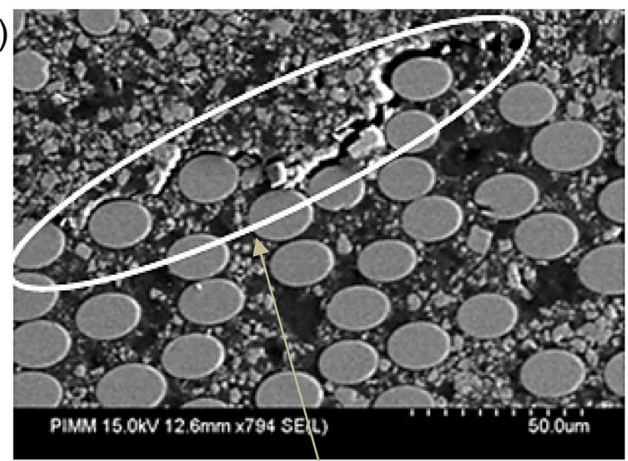

Interfacial

degradation

Figure 11. SEM observations of the composite microsture (a) before aging, after 100 and $500 \mathrm{~h}(\mathrm{~b}, \mathrm{c})$ at $50{ }^{\circ} \mathrm{C}$ and $(\mathrm{d}, \mathrm{e})$ at $90{ }^{\circ} \mathrm{C}$. Dark gray refers to the matrix, light gray refers to the fibers, white refers to the chlak particles and the black refers to voids. [Color figure can be viewed at wileyonlinelibrary.com]

The experimental data obtained by FTIR analysis are compared to the gravimetric model reported above as shown in Figure 14.

The results strongly suggest the existence of the two types of water: one following the Fickian kinetic till $772 \mathrm{~h}(\tau \approx 834 \mathrm{~s} /$ $\mathrm{mm})$ at $90{ }^{\circ} \mathrm{C}, 1792 \mathrm{~h}\left(\tau \approx 1272 \mathrm{~s}^{0.5} / \mathrm{mm}\right)$ at $70^{\circ} \mathrm{C}, 4797 \mathrm{~h}$ $\left(\tau \approx 2078 \mathrm{~s}^{0.5} / \mathrm{mm}\right)$ at $50{ }^{\circ} \mathrm{C}$ and $10336 \mathrm{~h}(\tau \approx 3050 \mathrm{~s} .5 / \mathrm{mm})$ at $25{ }^{\circ} \mathrm{C}$. A second type follows the sigmoidal kinetic till reaching $\tau$ after the same periods of time. Then, at $(t>\tau)$ a reverse in kinetics was recorded. This will be discussed later.

\section{Thermal Behavior}

Water molecules affect significantly the glass transition temperature of the material. The results of DMA tests show three behaviors in the $T_{g}$ evolution whatever the aging temperature. These behaviors are denoted, respectively, (I), (II), and (III) as it is shown in Figure 15(b).

In the first zone denoted (I), a considerable decrease in the $T_{g}$ values was observed, which duration depends on the aging temperature. It is clear that the lower the aging temperature is, the slower the decrease is and the longer is the phenomenon. At $25^{\circ} \mathrm{C}$, the glass transition temperature shows a decrease of only $4 \%$ after $1870 \mathrm{~h}\left(\approx 1300 \mathrm{~s}^{0.5} / \mathrm{mm}\right)$ of aging. At $50{ }^{\circ} \mathrm{C}$, a decrease of about $7 \%$ of the initial value was recorded after $540 \mathrm{~h}(\approx 700$ $\left.\mathrm{s}^{0.5} / \mathrm{mm}\right)$ compared to a decrease of $10 \%$ at $70{ }^{\circ} \mathrm{C}$ after only $40 \mathrm{~h}$ $(\approx 190 \mathrm{~s} .5 / \mathrm{mm})$ in immersion. The shortest period was registered by the temperature of $90^{\circ} \mathrm{C}$ where a decrease of $13 \%$ was recorded after only about $10 \mathrm{~h}\left(\approx 100 \mathrm{~s}^{0.5} / \mathrm{mm}\right)$. 


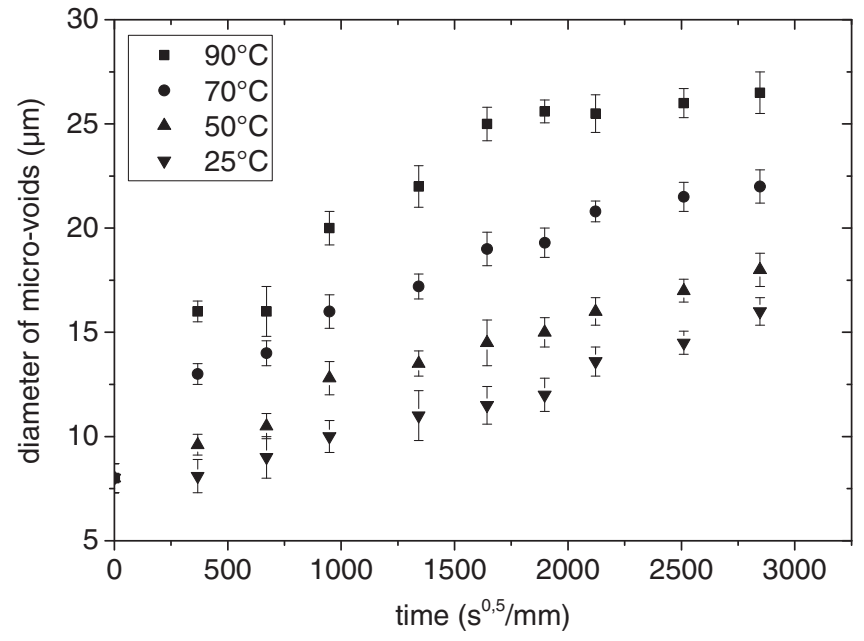

Figure 12. Evolution of the micro-porosities diameters during water immersion at different temperature based on a standard deviation measurement.

This decrease can be related to the plasticization effect of water. Indeed, when the temperature increases, the breaking rate of the interchains bonds increases resulting in decrease of the $T_{g} \cdot{ }^{38,39}$

The second zone, denoted (II), shows a significant increase in the glass transition temperature. This can be related to the postcrosslinking phenomenon, which causes an increase in the $T_{g}$ of the material. This phenomenon is generally observed in polymers, which fabrication process is very quick, so that the material is not fully crosslinked. ${ }^{40}$ In this case, the plasticization of the network
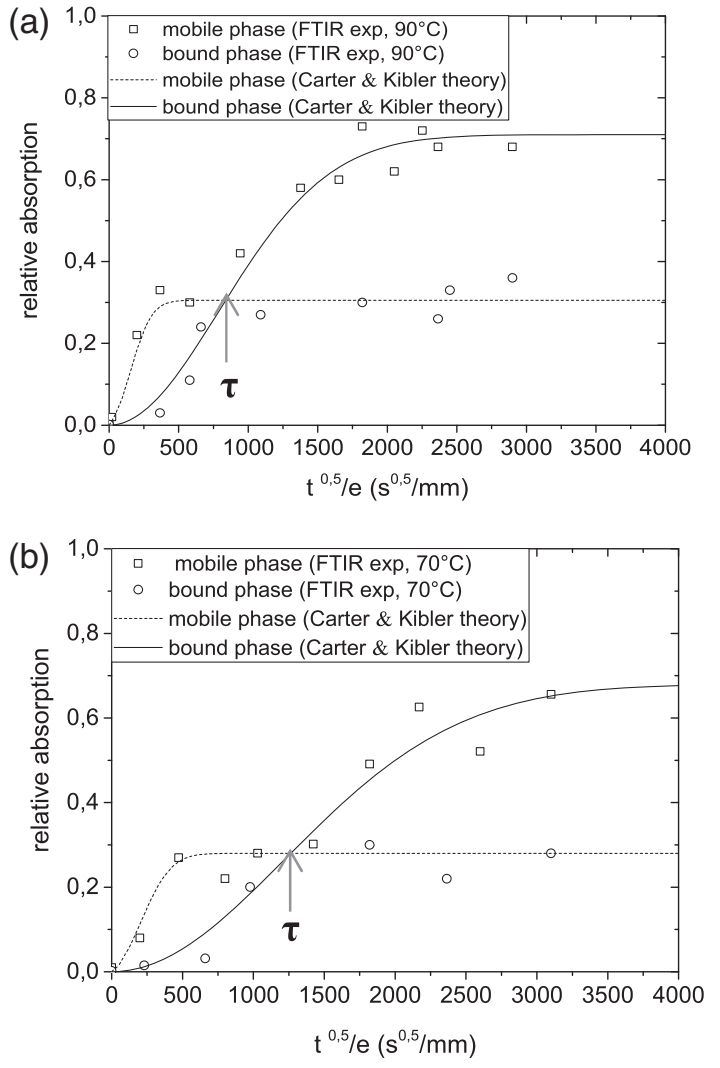

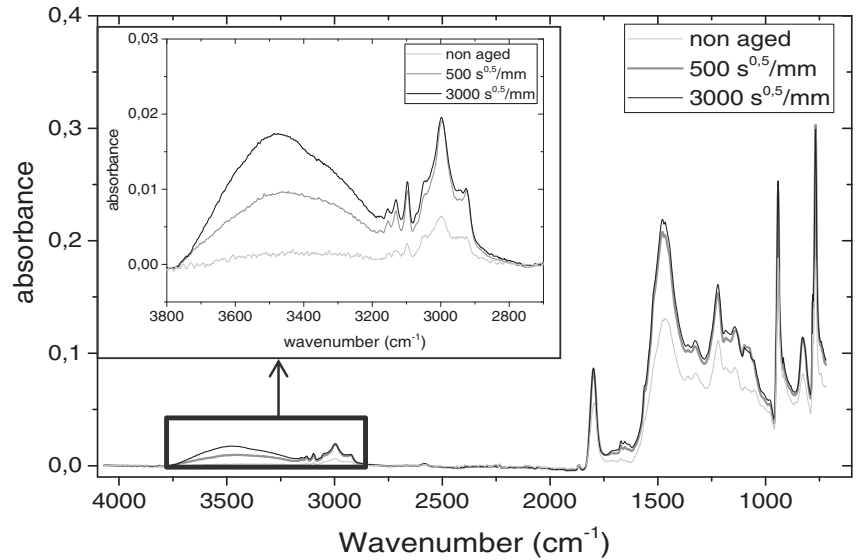

Figure 13. Evolution of FTIR peaks before (nonaged) and after immersion in water at $90{ }^{\circ} \mathrm{C}$.

by water allows the system to finish crosslinking. Such a result was widely observed by different authors in the literature. ${ }^{9,41,42}$

In order to verify the hypothesis of the "postcrosslinking" reaction in the studied material, thermal analysis by DSC were performed on unaged samples and aged at $90{ }^{\circ} \mathrm{C}$ after $120 \mathrm{~h}$ (corresponding to $320 \mathrm{~s}^{0.5} / \mathrm{mm}$ ).

The results in Figure 16 show an exothermal peak on the temperature range from 30 to $95^{\circ} \mathrm{C}$ (dashed curves). This peak is associated to the presence of post-crosslinking reaction due to incomplete polymerization of the polymer. ${ }^{43}$ The first heating cycle carried out on the
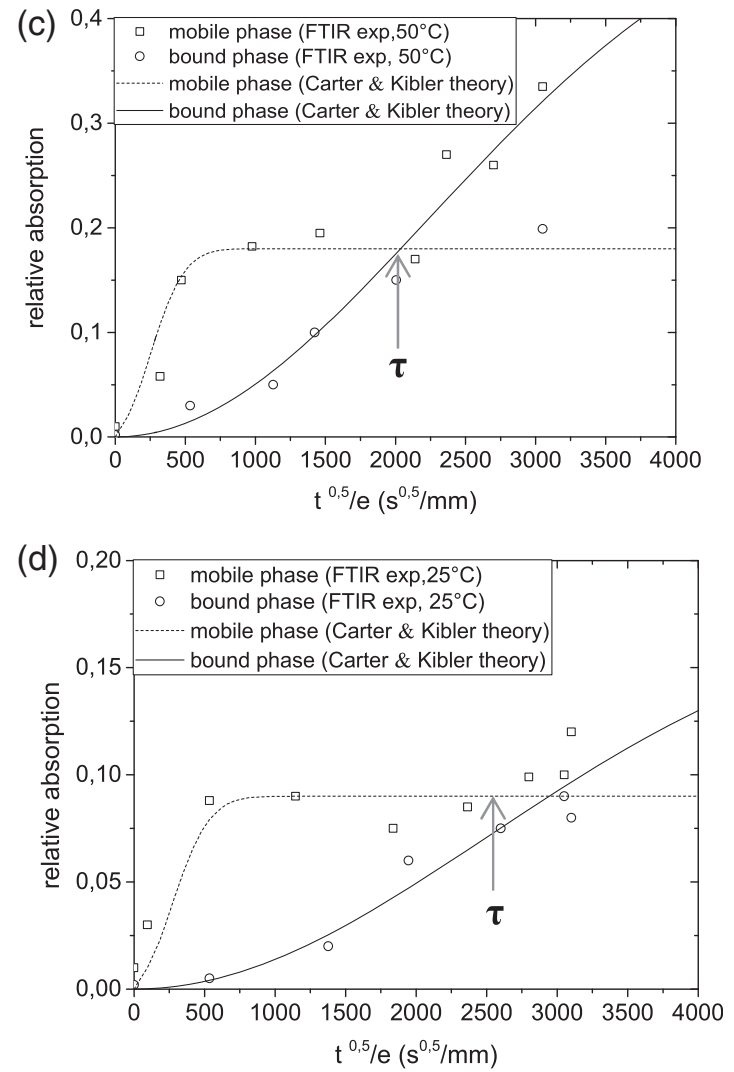

Figure 14. Comparaison between the model of both types of water (mobile and bound) and data estimated from FTIR experiments at (a) $90{ }^{\circ} \mathrm{C}$, (b) $70{ }^{\circ} \mathrm{C}$, (c) $50{ }^{\circ} \mathrm{C}$, and (d) $25^{\circ} \mathrm{C}$ 
(a)

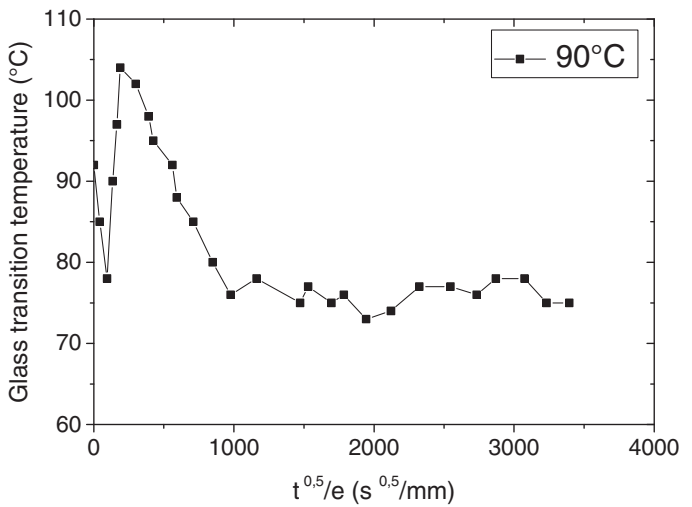

(c)

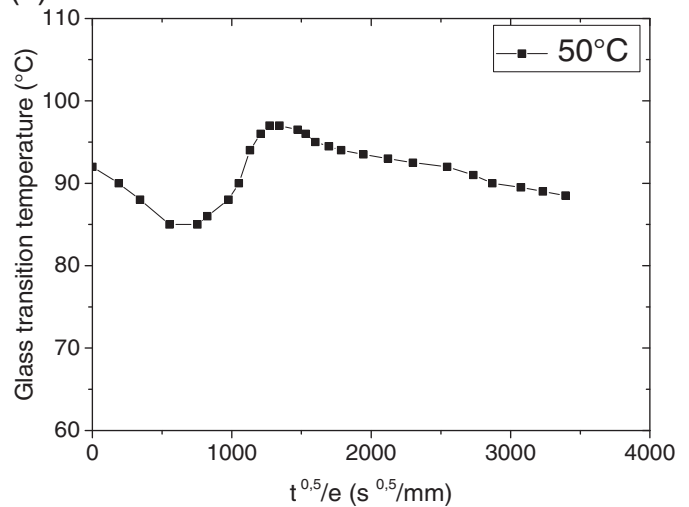

(b)

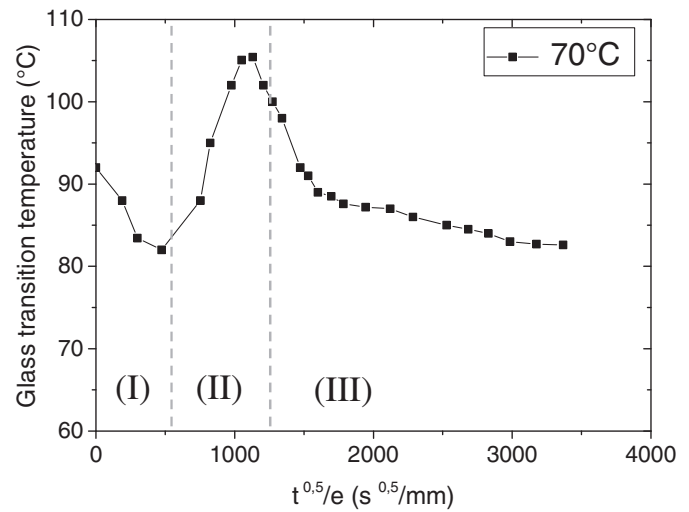

(d)

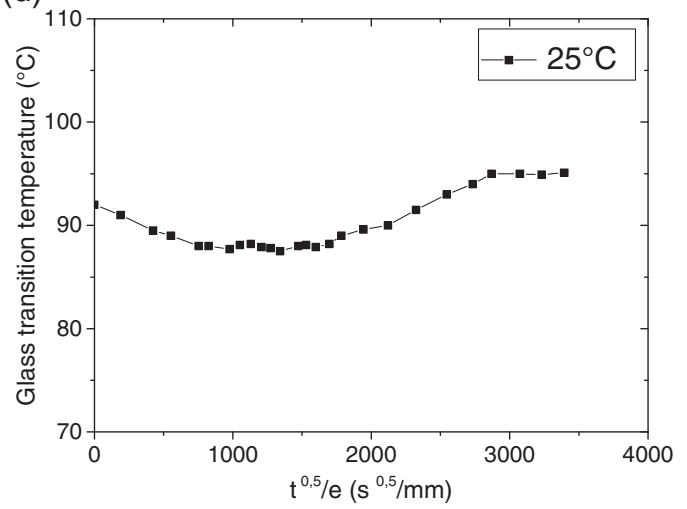

Figure 15. Evolution of the glass transition temperature versus the aging time at (a) $90{ }^{\circ} \mathrm{C}$, (b) $70{ }^{\circ} \mathrm{C},(\mathrm{c}) 50{ }^{\circ} \mathrm{C}$, and (d) $25{ }^{\circ} \mathrm{C}$.

aged specimen was followed by a second heating cycle shown by the continuous line in Figure 16. The result shows no exothermal reaction (no exothermal peak). Therefore, the polymer system was fully crosslinked during the first cycle. ${ }^{43}$

Finally (III), the glass transition temperature decreases till reaching a plateau where it remains constant.

The marked point to be retained here is the time at which theses phenomenon appear compared to the evolution of bound and

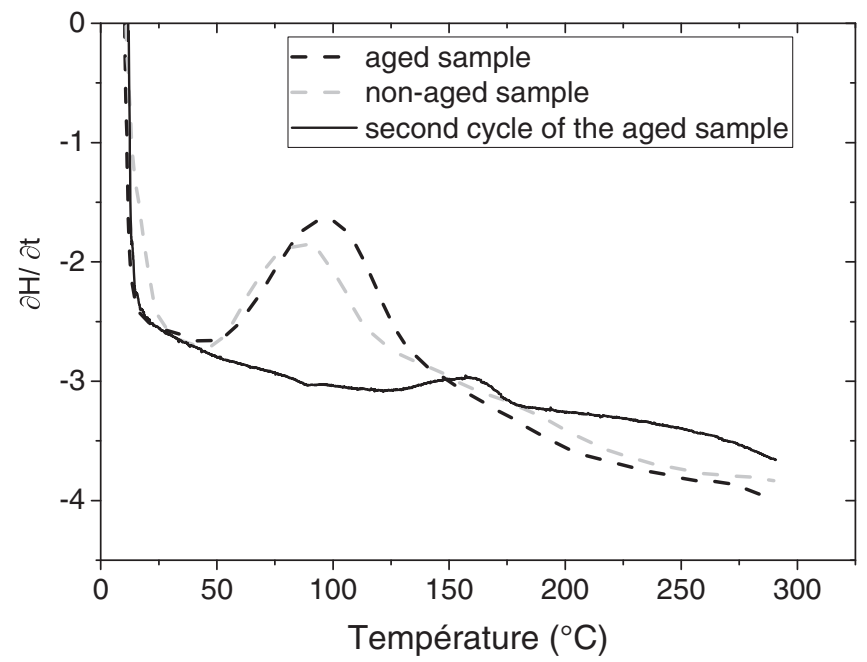

Figure 16. DSC thermograms of aged and nonaged samples. mobile water as described above. This will be discussed in the following section.

\section{DISCUSSION}

So far, we have reported and discussed the different results independently of each other.

The kinetic of water uptake in the SMC composite is well described by the model developed by Carter and Kibler ${ }^{19}$ as it is shown in Figure 3. It seems, as assumed in this model, that the equilibrium value is not influenced by temperature (Table I), because it is an intrinsic parameter of the studied material. These authors consider the nondependency of both $\beta$ and $\gamma$ parameters to temperature although they represent the motion of molecules. In this study, the results suggest their dependency on the aging temperature.

Despite the good agreement between the gravimetric results and the model developed by Carter and Kibler, there is a difference between the FTIR results and Carter and Kibler interpretation of the two types of solvent. They consider that the Fickian behavior is related to free/mobile water, while the sigmoidal behavior refers to bounded water molecules.

In a previous study, ${ }^{22}$ the authors have shown a paradoxical situation. They found that the mobile diffusing water in Carter and Kibler's theory is, indeed, the bound phase and vice versa. They explain that it is necessary to understand the bound and free water, respectively, as a rapid diffusion of molecules (due to 
(A)

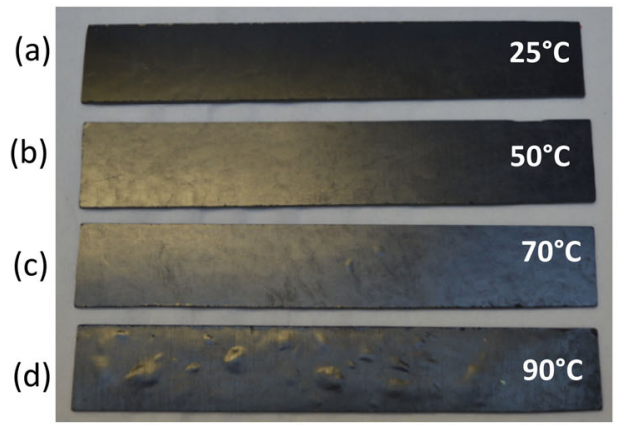

(B)

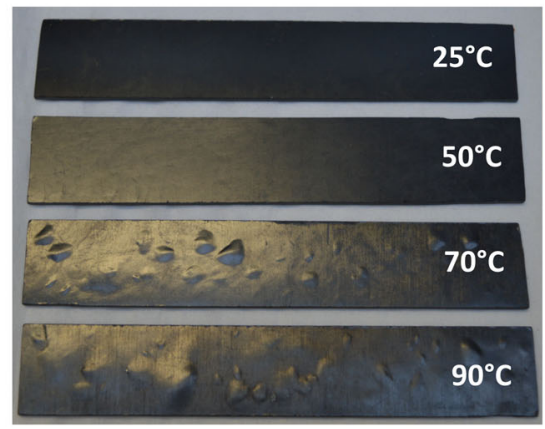

Figure 17. Swelling zones after (A) $500 \mathrm{~h}$ and (B) $2500 \mathrm{~h}$ of aging at (a) $25^{\circ} \mathrm{C}$, (b) $50{ }^{\circ} \mathrm{C}$, (c) $70{ }^{\circ} \mathrm{C}$, and (d) $90{ }^{\circ} \mathrm{C}$. [Color figure can be viewed at wileyonlinelibrary.com]

interactions between polar groups), and a slow diffusion of agglomerates of molecules in the microvoids (which do not have interactions with the polymer).

The results, summarized in Figure 14, show a nonnegligible dispersion but they are, someway, in a good agreement. In this study, the simultaneous exploitation of the FTIR analysis and gravimetric data allows us to propose another explanation of the trends observed in absorption. We could suppose a "biphasic" water absorption in the studied material. The diffusion of weakinteraction water (mobile water) starts at earlier periods of aging $(\mathrm{t}<\tau)$ with high tendencies following the Carter and Kibler's theory of mobile phase (Fickian diffusion kinetic). At $(t>\tau)$, this water continue increasing, and here, following the Carter and Kibler's theory of bound phase (Sigmoidal diffusion kinetic).

The kinetic of mobile water diffusion is governed by the presence of voids and cracks in the material. To explain, water absorption takes place, by diffusion and by capillarity, in micro-voids (Fickian diffusion kinetic). Gradual increase in water concentration in these regions causes progressive increase in osmotic pressure in these regions, which results in swelling zones (blisters shown in Figure 17).

The mechanism of crack propagation is generally based on the osmosis phenomenon, that is to say, generation of osmotic pressure between the external environment (water) and the internal environment (micro-pocket and interface area).

Exceeding a critical osmotic pressure induces of crack propagation as described in Figure 11(e) (new regions for water diffusion), hence an increase in free water sorption (Sigmoidal diffusion kinetic). The Gradient pressure has a significant effect on leaching calcium carbonate particles as it is described in Figure 9(b). Indeed, as the material is highly charged with $\mathrm{CaCO}_{3}$ particles (35\%) and as the osmotic pressure increases in the micro-voids and in the interface regions, neighboring particles get moved by the osmotic forced until reaching the external surfaces.

Similar trends were observed when analyzing the stronginteraction (bound) water at $(\mathrm{t}<\tau)$, these molecules follow the bound phase based on the theory of Carter and Kibler (Sigmoidal diffusion kinetic). This type (bound water) can be Wan Der Wals interaction, hydrogen bonding or polar interactions thus causing plasticization and lowering the transition temperature. Then at $(t>\tau)$, bound water reach the equilibrium state, thus, following the mobile phase of Carter and Kibler theory (Fickian diffusion kinetic). This can be explained by the fact that the overall network is plasticized (plateau observed in the glass transition temperature). We highlight the fact that free and bound water refer to diffusion kinetic and do not refer to interaction with polymer.

\section{CONCLUSIONS}

By using both gravimetric measurement and FTIR technique, we have demonstrated that the carter and Kibler's theory can quantitatively describe water diffusion in SMC composite. In addition, by using FTIR, we have correlated the two types of water assumed in the theory. The paradoxical situation in the given explanation is that the "free" diffusing molecules in the theory of Carter and Kibler is effectively our mobile water until reaching a specific time $\tau$, but beyond, it is the bound phase, and vice versa.

To summarize the process of water diffusion in the present material, we suggest the three steps as follow

- At the beginning of sorption, free and bound water molecules diffuse into microvoids of material (following Fickian diffusion kinetic) and in the polymer network (following sigmoidal kinetic diffusion).

- After a given period of immersion (depending on the temperature), the bound molecular water become saturated and the sorption reaches a quasiequilibrium state (Fickian diffusion kinetic). A week interaction between water molecules and the polymer system is marked, shown by the plateau in the $T_{g}$ evolution and referring to bound solvent.

- Osmotic pressure increases in the existing micro-voids, following Fickian diffusion kinetic. Two phenomenons were observed: decohesion between glass fibers and matrix leading to formation of blisters, and decohesion between calcium carbonate agglomerates and matrix leading to calcium carbonate release. These damages cause the appearance of new microporosities, and therefore, an increase in water sorption (sigmoidal diffusion kinetic).

The free water continues to be important as the presence of cracks enhance the sorption until reaching the real equilibrium.

\section{ACKNOWLEDGMENTS}

This work is supported by Ecole des Arts et Métiers ParisTechFrance and Ecole Nationale d'Ingénieurs de Sousse-Université de Sousse-Tunisie. 


\section{REFERENCES}

1. Berthet, J. F.; Ferrier, E.; Hamelin, P. Construct. Build Mater. 2005, 19, 223.

2. Rochdi, E. H.; Bigaud, D.; Ferrier, E.; Hamelin, P. Compos. Struct. 2006, 72, 69.

3. Shao, Y.; Kouadio, S. J. Compos. Construct. 2002, 6, 280.

4. Cabral-Fonseca, S.; Correia, J. R.; Rodrigues, M. P.; Branco, F. A. Strain. 2012, 48, 162.

5. Shen, C.-H.; Springer Moisture, G. S. Moisture absorption and desorption of composite materials. In Absorption and Desorption of Composite Materials - chi-Hung Shen, George S, Springer: Michigan, 1976.

6. Starkova, O.; Buschhorn, S. T.; Mannov, E.; Schulte, K.; Aniskevich, A. Eur. Polym. J. 2013, 49, 2138.

7. Joliff, Y.; Belec, L.; Heman, M. B.; Chailan, J. F. Comput. Mater. Sci. 2012, 64, 141.

8. Lassila, L. V. J.; Nohrström, T.; Vallittu, P. K. Biomaterials. 2002, 23, 2221.

9. Zhou, J.; Lucas, J. P. Polymer. 1999, 40, 5505.

10. Ibrahim, G.; Casari, P.; Jacquemin, F.; Freour, S.; Clement, A.; Celino, A.; Khalil, K. J Compos Mater. 2018, 52, 1073.

11. Xiao, G. Z.; Shanahan, M. E. R. Polymer. 1998, 39, 3253.

12. Xiao, G. Z.; Shanahan, M. E. R. J. Appl. Polym. Sci. 1998, 69, 363.

13. Tcharkhtchi, A.; Bronnec, P. Y.; Verdu, J. Polymer. 2000, 41, 5777.

14. Antoon, M. K.; Koenig, J. L. J Polym Sci: Polym Phys Ed. 1981, 19, 197.

15. Apicella, A.; Migliaresi, C.; Nicolais, L.; Iaccarino, L.; Roccotelli, S. Composites. 1983, 14, 387.

16. Dhakal, H. N.; Zhang, Z. Y.; Richardson, M. O. W. Compos Sci Technol. 2007, 67, 1674.

17. Rashdi, A. A. A.; Sapuan, S. M.; Ahmad, M. M. H. M.; Khalina, A. J Food, Agricul Environ. 2009, 7, 908.

18. Kumosa, L.; Benedikt, B.; Armentrout, D.; Kumosa, M. Compos. A: Appl. Sci. Manuf. 2004, 35, 1049.

19. Carter, H. G.; Kibler, K. G. J Compos Mater. 1978, 12, 118.

20. Boukhoulda, F. B.; Guillaumat, L.; Lataillade, J. L.; AddaBedia, E.; Lousdad, A. Mater Des. 2011, 32, 4080.
21. Camino, G.; Luda, M. P.; Polishchuk, A. Y.; Revellino, M.; Blancon, R.; Merle, G.; Martinez-Vega, J. J. Compos Sci Technol. 1997, 57, 1469.

22. Popineau, S.; Rondeau-Mouro, C.; Sulpice-Gaillet, C.; Shanahan, M. E. R. Polymer. 2005, 46, 10733.

23. Maggana, C.; Pissis, P. J. Polym. Sci. B. 1999, 37, 1165.

24. Vanlandingham, M. R.; Eduljee, R. F.; Gillespie, J. W. J. Appl. Polym. Sci. 1999, 71, 787.

25. Barrie, J. A.; Sagoo, P. S.; Johncock, P. J. Membr. Sci. 1984, 18, 197.

26. Feng, J.; Berger, K. R.; Douglas, E. P. J. Mater. Sci. 2004, 39, 3413.

27. Primeau, N.; Vautey, C.; Langlet, M. Thin Solid Films. 1997, 310, 47.

28. Bellenger, V.; Verdu, J.; Francillette, J.; Hoarau, P.; Morel, E. Polymer. 1987, 28, 1079.

29. Musto, P.; Ragosta, G.; Mascia, L. Chem. Mater. 2000, 12, 1331.

30. Dholakiya, B. In Polyester; Saleh, H. E.-D., Ed., InTech: India, 2012.

31. Frisch, H. L. J. Appl. Polym. Sci. 1970, 14, 1657.

32. Hinkley, J. A.; Connell, J. W. In Long-Term Durability of Polymeric Matrix Composites; Pochiraju, K. V.; Tandon, G. P.; Schoeppner, G. A., Eds., Springer US: Boston, MA, 2012. p. 1.

33. Liao, K.; Schultheisz, C. R.; Hunston, D. L. Compos. Part B Eng. 1999, 30, 485.

34. Shanahan, M. E. R.; Auriac, Y. Polymer. 1998, 39, 1155.

35. Haddar, N.; Ksouri, I.; Kallel, T.; Mnif, N. Polym. Compos. 2014, 35, 501.

36. Alawsi, G.; Aldajah, S.; Rahmaan, S. A. | Request PDF. 2009, 7, 2506.

37. Athijayamani, A.; Thiruchitrambalam, M.; Natarajan, U.; Pazhanivel, B. Mater. Sci. Eng. A. 2009, 517, 344.

38. ten Brinke, G.; Karasz, F. E.; Ellis, T. S. Macromolecules. 1983, 16, 244.

39. Ellis, T. S.; Karasz, F. E. Polymer. 1984, 25, 664.

40. Bergmark, P.; Flodin, P. Polymer. 1987, 28, 1662.

41. Ghorbel, I.; Valentin, D. Polym. Compos. 1993, 14, 324.

42. Maurin, R. Compos. A: Appl. Sci. Manuf. 2009, 40, 1024.

43. Salmoria, G. V.; Ahrens, C. H.; Fredel, M.; Soldi, V.; Pires, A. T. N. Polym. Test. 2005, 24, 157. 